\title{
In Vitro Sonothrombolysis of Human Blood Clots: Preliminary Results
}

\author{
B. Petit ${ }^{1,2}$, E. Gaud ${ }^{2}$, F. Polliart ${ }^{1,2}$, D. ColeVret ${ }^{2}$, M. Schneider ${ }^{2}$, \\ I. GUILBERT-BRIGger ${ }^{2}$, F. YAN ${ }^{2}$, F. TRANQUART ${ }^{2}$, E. AllÉmANn ${ }^{1}$ \\ ${ }^{1}$ School of Pharmaceutical Sciences, University of Geneva, University of Lausanne, Geneva, Switzerland \\ ${ }^{2}$ Bracco Research S.A, Plan-les-Ouates, Geneva, Switzerland \\ E-mails: benedicte.petit@unige.ch (B. Petit), eric.allemann@unige.ch (E. Allémann)
}

Sci Pharm. 2010; 78: 688

doi:10.3797/scipharm.cespt.8.PNM18

Ischemic stroke results from a cerebral vessel occlusion by a blood clot. Treatments are intended to restore the cerebral blood flow as soon as possible to avoid major brain damage. Intravenous administration of recombinant tissue plasminogen activator (rtPA) is the only thrombolytic drug approved for treatment of acute ischemic stroke [1].

In vitro and in vivo studies have shown that rtPA in combination with ultrasound and microbubbles can improve clot lysis [2]. However, the exact mechanisms involved in this sonothrombolysis process remain unknown. Additionnally, the optimal conditions for clot lysis are not mastered.

The aim of the present work was to set up a robust in vitro human clot model and to evaluate the thrombolytic effect of rtPA and microbubbles while varying various acoustic parameters.

Practically, fresh whole human blood clots were formed after three hours at $37^{\circ} \mathrm{C}$ in $200 \mu \mathrm{L}$ glass micropipettes through which a silk suture had been threaded. The clots were characterized by their diameter, by scanning electron microscopy (SEM) and by immunostaining. The clots were placed in a cell mounted with transparent Mylar® films, and filled with human plasma. The cell was then placed in a thermostated water bath $\left(37^{\circ} \mathrm{C}\right)$ and the clot was exposed to different experimental conditions of ultrasound $(0.65 \mathrm{MHz})$, rtPA and microbubble suspensions in a continuous infusion. Every five minutes during 60 minutes photographs were taken and analysed to determine the mean diameter decrease of the clot.

The clots had an initial diameter of $0.89 \pm 0.06 \mathrm{~mm}$ (mean diameter $\pm \mathrm{sd}$ ). In the presence of rtPA at $3 \mu \mathrm{g} / \mathrm{mL}$, microbubbles and ultrasound, the mean clot diameter dropped by more than $0.5 \mathrm{~mm}$ in $60 \mathrm{~min}$. Under SEM and with the immunostaining, sonothrombolysis effects were clearly observed.

These preliminary experiments are encouraging and will enable a thorough evaluation of the synergetic effects of microbubbles, ultrasound and rtPA.

[1] Adams H P, Del Zoppo G, Alberts M J, Bhatt D L, Brass L, Furlan A, Grubb R L, Higashida R T, Jauch E C, Kidwell C, Lyden P D, Morgenstern L B, Qureshi A I, Rosenwasser R H, Scott P A, Wijdicks E F M. Guidelines for the Early Management of Adults With Ischemic Stroke. Stroke. 2007; 38: 16551711. doi:10.1161/STROKEAHA.107.181486

[2] Meairs S, Culp W. Microbubbles for Thrombolysis of Acute Ischemic Stroke. Cerebrovasc Dis. 2009; 27 (Suppl 2): 55-65. doi:10.1159/000203127 